\title{
Perancangan Model Organization Capital Readiness pada Institut Teknologi Sepuluh Nopember, Surabaya
}

\author{
Isabella Sekarwangi Boedhiantari, Naning Aranti Wessiani \\ Departemen Teknik Industri, Fakultas Teknologi Industri, Institut Teknologi Sepuluh Nopember (ITS) \\ e-mail: isabellasekarwangi@gmail.com,wessiani@ie.its.ac.id
}

\begin{abstract}
Abstrak-Perubahan status Institut Teknologi Sepuluh Nopember menjadi Perguruan Tinggi Negeri Badan Hukum (PTNBH) membuat ITS harus menyesuaikan tata laksana kinerjanya sesuai dengan tatanan PTNBH. Dalam menghadapi perubahan status menjadi PTNBH, diperlukan adanya manajemen perubahan oleh ITS. Manajemen perubahan merupakan salah satu komponen yang paling penting dalam pelaksanaan manajemen strategi untuk membantu sebuah organisasi dalam mencapai tujuannya. Salah satu area yang mengalami perubahan adalah organisasi. Perubahan yang dilakukan pada organisasi sebagai aset tak berwujud dapat menjadi keunggulan kompetitif guna pengembangan ITS secara berkelanjutan. Salah satu upaya yang dilakukan ITS dalam mengembangkan sustainabilitas organisasinya adalah dengan membangun sebuah model dari Organization Capital Readiness yang mampu memberikan gambaran tingkat maturitas ITS. Penelitian ini bertujuan untuk merancang sebuah model Organization Capital Readiness dengan framework Organization Readiness Assessment System sebagai dasar aspek-aspek didalamnya. Selain itu, penelitian ini bertujuan untuk merancang mekanisme sistem pengukuran model maturitas Organization Capital Readiness berdasarkan framework Process and Enterprise Maturity Model dan Peraturan Kepala Badan Pengawasan Keuangan dan Pembangunan Nomor 4 Tahun 2016 mengenai Penilaian Maturitas Sistem Pengendalian Intern Permerintah serta mekanisme sistem penyusunan perubahan organization capital dengan framework Organization Change Agenda. Hasil dari penelitian ini berupa kerangka model maturitas Organization Capital Readiness ITS, mekanisme sistem pengukuran model maturitas, dan mekanisme sistem penyusunan perubahan modal organisasi. Kerangka yang diusulkan pada penelitian ini juga akan digunakan ITS dalam menilai tingkat maturitas organisasinya.
\end{abstract}

Kata Kunci-Organization Capital Readiness, Model Maturitas, Organization Readiness Assessment System, Organization Change Agenda

\section{PENDAHULUAN}

$\mathrm{P}$ endidikan merupakan pondasi yang mendukung kemajuan suatu bangsa dalam menghadapi persaingan global. Dalam hal ini, pemerintah Indonesia memiliki strategistrategi tertentu untuk menjawab tantangan era globalisasi. Maka dari itu, terjadi banyak transformasi sistem pendidikan di Indonesia tak terkecuali pendidikan tinggi. Berdasarkan Peraturan Pemerintah Republik Indonesia Nomor 58 Tahun 2013, misi utama Pendidikan Tinggi adalah bertujuan mencari, menemukan, mendiseminasikan, dan menjunjung tinggi kebenaran. Agar misi tersebut dapat diwujudkan, maka Perguruan Tinggi sebagai penyelenggara Pendidikan Tinggi harus bebas dari pengaruh, tekanan, dan kontaminasi apapun seperti kekuatan politik dan/atau kekuatan ekonomi, sehingga Tridharma Perguruan Tinggi dapat dilaksanakan berdasarkan kebebasan akademik dan otonomi keilmuan. Untuk itu, berdasarkan Undang-Undang Nomor 12 Tahun 2012 Pasal 65 dan Peraturan Pemerintah Nomor 4 Tahun 2014 Pasal 27, terdapat tiga jenis perguruan tinggi negeri berdasarkan tata pengelolaan keuangannya, yaitu PTNSATKER, PTN-BLU, dan PTNBH. PTN-SATKER atau Perguruan Tinggi Negeri dengan Penerimaan Negara Bukan Pajak (PNBP) mengelola keuangannya berdasarkan aturan pemerintah negara, sedangkan PTN-BLU merupakan Perguruan Tinggi Negeri Badan Layanan Umum yang dapat mengelola keuangannya lebih fleksibel dalam pengelolaan dana yang berasal dari masyarakat dan biaya layanan ditetapkan oleh Menteri Keuangan. Kemudian, PTNBH merupakan Perguruan Tinggi Negeri Badan Hukum dimana memiliki otonomi yang lebih luas dalam pengelolaan keuangannya.

Institut Teknologi Sepuluh Nopember merupakan salah satu perguruan tinggi negeri di Surabaya, Jawa Timur. Berdasarkan Peraturan Pemerintah Nomor 83 Tahun 2014, Institut Teknologi Sepuluh Nopember ditetapkan sebagai salah satu perguruan tinggi yang mengalami perubahan status dari PTN-BLU berubah menjadi PTNBH. Hal ini menyebabkan ITS memiliki kewenangan untuk mengelola organisasi, keuangan, sumber daya manusia, dan infrastruktur dengan tata kelola yang baik karena pemerintah tetap menjalankan fungsi pemantauan dan evaluasi. Oleh karena itu ITS harus mengubah birokrasi sesuai dengan tatanan PTNBH. Dalam pengimplementasian PTNBH terdapat delapan area kunci perubahan reformasi birokrasi yang harus dilakukan oleh ITS. (Tabel 1)

Dis amping itu, Prof. Ir Priyo Suprobo MSC PhD, Ketua Senat ITS, menjelaskan bahwa ada beberapa aspek yang perlu diperhatikan dalam menghadapi PTNBH, yaitu budaya kerja karena dapat memengaruhi kegiatan manajemen. Kemudian, menurut Direktur Jenderal Kelembagaan IPTEK DIKTI, Dr. Ir. Patdono Suwignjo, M.Eng. Sc., terdapat banyak kompeten yang harus dibangun pada ITS dengan status PTNBH, yaitu menghasilkan tenaga yang terampil dan berpendidikan tinggi, memiliki askes, mampu berinovasi, menjadi institut yang kompetitif, dan melakukan perbaikan tata kelola. Transformasi budaya mutu dalam organisasi dan sistem manajemen ITS juga dibutuhkan untuk memenuhi tuntutan Good University Governance dan World Class University yang sejalan dengan agenda pembangunan 
Tabel 2.

Delapan Area Kunci Perubahan ITS dalam PTNBH

\begin{tabular}{|c|c|}
\hline Area Perubahan & Tujuan \\
\hline Organisasi & $\begin{array}{l}\text { Organisasi yang tepat fungsi dan tepat } \\
\text { ukuran. }\end{array}$ \\
\hline Tata Laksana & $\begin{array}{l}\text { Sistem, proses, dan prosedur kerja yang } \\
\text { jelas, efektif, efisien, terukur, dan sesuai } \\
\text { dengan prinsip-prinsip good governance. }\end{array}$ \\
\hline $\begin{array}{l}\text { Peraturan } \\
\text { Perundang- } \\
\text { undangan }\end{array}$ & $\begin{array}{l}\text { Regulasi yang lebih tertib, tidak tumpang } \\
\text { tindih, dan kondusif. }\end{array}$ \\
\hline Sumber Daya & SDM apartur yang berintegritas, netral, \\
\hline Manusia & $\begin{array}{l}\text { kompeten, kapabel, profesional, berkinerja } \\
\text { tinggi, dan sejahtera. }\end{array}$ \\
\hline Pengawasan & $\begin{array}{l}\text { Meningkatnya penyelenggaraan organisasi } \\
\text { yang bersih dan bebas KKN. }\end{array}$ \\
\hline Akuntabilitas & $\begin{array}{l}\text { Meningkatnya kapasitas dan akuntabilitas } \\
\text { kinerja birokrasi. }\end{array}$ \\
\hline Pelayanan & $\begin{array}{l}\text { Pelayanan prima sesuai kebutuhan dan } \\
\text { harapan semua pemangku kepentingan. }\end{array}$ \\
\hline $\begin{array}{l}\text { Pola Pikir dan } \\
\text { Budaya }\end{array}$ & $\begin{array}{l}\text { Birokrasi dengan integritas dan kinerja } \\
\text { yang tinggi. }\end{array}$ \\
\hline Organisasi & $\begin{array}{l}\text { Organisasi yang tepat fungsi dan tepat } \\
\text { ukuran. }\end{array}$ \\
\hline Tata Laksana & $\begin{array}{l}\text { Sistem, proses, dan prosedur kerja yang } \\
\text { jelas, efektif, efisien, terukur, dan sesuai } \\
\text { dengan prinsip-prinsip good governance. }\end{array}$ \\
\hline $\begin{array}{l}\text { Peraturan } \\
\text { Perundang- } \\
\text { undangan }\end{array}$ & $\begin{array}{l}\text { Regulasi yang lebih tertib, tidak tumpang } \\
\text { tindih, dan kondusif. }\end{array}$ \\
\hline
\end{tabular}

Indonesia dan global pasca 2015 dari Xillenium Development Goals menuju Sustainable Development Goals. Tujuan dari GUG adalah untuk mewujudkan sasaran strategis ITS, yaitu kontribusi nasional dan reputasi internasional.

Maka dari itu dalam menghadapi PTNBH, Institut Teknologi Sepuluh Nopember perlu melakukan manajemen perubahan. Manajemen perubahan merupakan serangkaian proses yang digunakan untuk memastikan bahwa perubahan strategis yang signifikan dalam organisasi dilakukan secara terkontrol dan sistematis [1]. Tujuan dari manajemen perubahan adalah untuk mengatasi resistensi terhadap perubahan dalam rangka meningkatkan keterlibatan dan pencapaian tujuan organisasi untuk transformasi efektif. Perubahan dapat dilakukan pada aset fisik dan aset tak berwujud. Perubahan yang dilakukan pada aset tak berwujud (intangible asset) dapat menjadi keunggulan kompetitif guna pengembangan organisasi ITS secara berkelanjutan karena sifatnya yang unik dan sulit untuk ditiru oleh kompetitor. Salah satunya adalah aspek organisasi sesuai dengan delapan area kunci perubahan birokrasi ITS dalam menghadapi perubahan status PTNBH. Nilai aset tak berwujud berasal dari seberapa baik hal tersebut dapat menyesuaikan dengan strategi organisasi. Keselarasan dengan tujuan proses bisnis internal yang terintegrasi satu sama lain dapat membantu organisasi dalam mencapai potensi produktivitas yang maksimal dan dapat menciptakan sinergitas pada organisasi, serta organisasi dapat memahami posisinya di tengah persaingan dengan lebih mudah dan akurat.

Untuk itu, kesiapan kapital organisasi (Organization Capital Readiness) perlu dikembangkan oleh Institut
Tabel 1.

Pengertian Aspek OCR ITS

\begin{tabular}{|c|c|}
\hline Aspek & Penjelasan \\
\hline $\begin{array}{l}\text { Proses utama } \\
(\text { core processes) }\end{array}$ & $\begin{array}{l}\text { Serangkaian kegiatan utama pada proses } \\
\text { bisnis ITS dalam menciptakan nilai dari } \\
\text { produk/jasa yang dihasilkan untuk } \\
\text { menciptakan keunggulan yang kompetitif }\end{array}$ \\
\hline $\begin{array}{l}\text { Pendekatan } \\
\text { manajemen } \\
\text { (management } \\
\text { approach) }\end{array}$ & $\begin{array}{l}\text { Kemampuan ITS dalam memanajemen } \\
\text { organisasi agar sesuai dengan nilai dan tata } \\
\text { laksana yang jelas, selaras, dan terintegrasi } \\
\text { serta dapat dipertanggungjawabkan }\end{array}$ \\
\hline Budaya (culture) & $\begin{array}{l}\text { Cara ITS dalam mengembangkan nilai } \\
\text { yang hendak dibangun dalam organisasi } \\
\text { agar organisasi dapat berkembang dan } \\
\text { menjadi keunggulan yang kompetitif }\end{array}$ \\
\hline $\begin{array}{l}\text { Sinergitas } \\
\text { (synergy) }\end{array}$ & $\begin{array}{l}\text { Kemampuan ITS dalam membangun } \\
\text { hubungan kerjasama internal yang } \\
\text { produktif serta kemitraan yang harmonis } \\
\text { dengan para pemangku kepentingan, } \\
\text { untuk mencapai sutu tujuan yang lebih } \\
\text { baik dan lebih besar }\end{array}$ \\
\hline $\begin{array}{l}\text { Sikap terhadap } \\
\text { perubahan } \\
\text { (change } \\
\text { resistance) }\end{array}$ & $\begin{array}{l}\text { Kemampuan ITS dalam memahami dan } \\
\text { memanajemen reaksi dari suatu perubahan } \\
\text { yang terjadi pada organisasi }\end{array}$ \\
\hline
\end{tabular}

Teknologi Sepuluh Nopember dalam rangka menghadapi perubahan iklim dan budaya kerja PTNBH. Pada framework pengukuran kinerja Balanced Scorecard, learning and growth merupakan perspektif dasar yang menggambarkan intangible asset dan perannya dalam mendukung strategi. Kesiapan kapital organisasi merupakan kemampuan organisasi dalam melakukan mobilisasi dan mempertahankan proses perubahan yang dibutuhkan untuk menjalankan strategi. Organization capital memiliki kemampuan integrasi sehingga aset human capital, information capital, serta aset fisik dan keuangan tidak hanya selaras dengan strategi, namun semuanya terintegrasi dan bekerja sama untuk mencapai tujuan strategi organisasi. Sistem manajemen pengetahuan dapat menjadi kunci pada proses sharing knowledge kapital organis asi tersebut [2].

Kesiapan kapital organisasi dilakukan setelah organisasi tersebut mampu menyelaraskan kapital organisasi terhadap strategi organisasi dan mampu mengidentifikasi level kesiapan kapital organisasi melalui pendekatan Organization Maturity Model dan Organization Readiness Assessment System. Dengan mengetahui posisi kesiapan kapital organisasi, maka dapat, dilakukan manajemen perubahan sesuai dengan tata nilai yang diinginkan agar organisasi tersebut dapat menciptakan nilai secara berkelanjutan.

Dalam penelitian ini, dilakukan perancangan model Organization Capital Readiness dengan pendekatan Organization Maturity Model, Organization Readiness Assessment System (ORAS), Process and Enteprise Maturity Model, Penilaian Maturitas Sistem Pengendalian Intern Pemerintah sesuai Perka Nomor 4 Tahun 2016, dan Organization Change Agenda (OCA) guna membantu Institut Teknologi Sepuluh Nopember dalam penyelerasan dan integrasi antara intangible asset dengan strategi organisasi yang berubah seiring dengan status ITS sebagai PTNBH sehingga ITS dapat melakukan pengembangan organisasi secara berkelanjutan. 
Tabel 3.

Kerangka Model Maturitas OCR ITS

\begin{tabular}{ccccc}
\hline \hline Nilai & Level & Penjelasan & Evidence & $\begin{array}{c}\text { Penanggung } \\
\text { Jawab }\end{array}$ \\
\hline & L-1 & & \\
L-2 & & \\
L-3 & & \\
L-4 & \\
L-5 & \\
\hline
\end{tabular}

Tabel 4.

Kerangka Kuesioner Awal Pengukuran Maturitas OCR ITS

Kuesioner Pengukuran Level Maturitas OCRdi ITS

Berilah tanda v (checklist) untuk menjawab pertanyaan mengenai level maturitas kesiapan modal organisasi di Institut Teknologi Sepuluh Nopember

\begin{tabular}{llll}
\multicolumn{4}{c}{ Sepuluh Nopember } \\
\hline \multicolumn{4}{c}{ Aspek } \\
Nilai & Ya & Tidak \\
1 & & & \\
2 & & & \\
3 & & & \\
4 & & \\
5 & & \\
\hline \hline
\end{tabular}

\section{METODOLOGI PENELITIAN}

\section{A. Tahap Identifikasi dan Perumusan Masalah}

Pada Tahap Identifikasi dan Perumusan Masalah akan dijabarkan mengenai proses dari tahap identifikasi dan perumusan masalah yang terdiri dari: tahap identifikasi kondisi eksisting mengenai organization capital pada Institut Teknologi Sepuluh Nopember Surabaya; perumusan masalah, penetapan tujuan, dan penetapan ruang lingkup penelitian; studi literatur; dan studi lapangan.

\section{B. Tahap Pengumpulan Data}

Pada Tahap Pengumpulan Data akan dilakukan proses pengumpulan data komponen strategis ITS seperti visi, misi, strategi, dan tata nilai ITS yang digunakan acuan dalam merancang Organization Capital Readiness (OCR) pada Institut Teknologi Sepuluh Nopember. Selain itu, dilakukan benchmark terhadap organisasi profit dan organisasi nonprofit. Tujuan dari benchmark ini adalah untuk memahami dan membandingkan keadaan ITS dalam melakukan manajemen perubahan seiring perubahan status PTNBH sehingga mendapatkan cara untuk mengembangkan organisasinya, utamanya dalam organization capital. Metode yang digunakan dalam melakukan benchmark adalah dengan melakukan wawancara ke pihak expert dari instansi terkait.

\section{C.Tahap Perancangan}

Pada Tahap Perancangan akan dilakukan perancangan Organization Capital Readiness berdasarkan data-data yang telah didapatkan. Tahap ini dibagi menjadi beberapa tahapan yakni identifikasi aspek-aspek pada OCR ITS, perancangan maturity model OCR ITS, perancangan mekanisme sistem pengukuran OCR ITS, dan perancangan mekanisme sistem penyusunan perubahan organization capital dengan Organization Change Agenda.

\section{D.Tahap Analisis dan Interpretasi Data}

Pada bagian ini akan dilakukan analisis terhadap hasil pengolahan data yang diperoleh sebelumnya, yaitu analisis

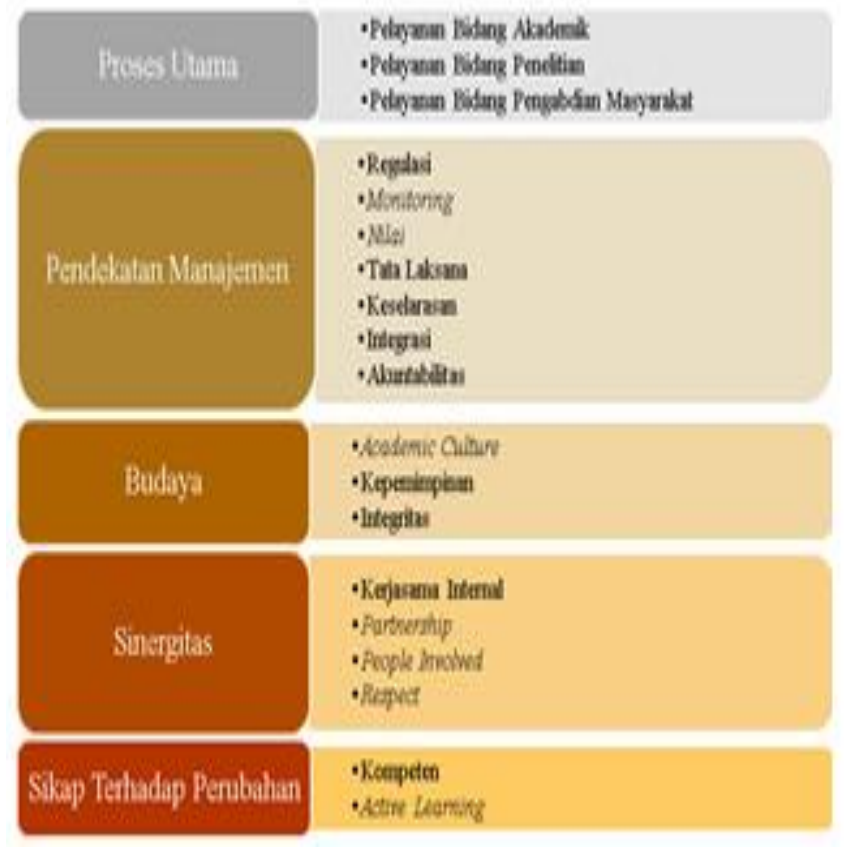

Gambar 1. Nilai-nilai pada Tiap Aspek OCR ITS.

kondisi eksisting ITS, analisis Organization Capital Readiness, analisis maturiry level Organization Capital Readiness, analisis mekanisme sistem pengukuran Organization Capital Readiness, dan analisis mekanisme perubahan Organization Capital dengan Organization Change Agenda.

\section{E. Tahap Penarikan Kesimpulan}

Pada tahap ini akan dilakukan penarikan kesimpulan dan pemberian saran terhadap penelitian Tugas Akhir.

\section{PENGUMPULAN DAN PENGOLAHAN DATA}

\section{A. Pengumpulan Data - Komponen Strategis ITS}

Tahap awal pada penilitian ini adalah mengidentifikasi visi, misi, tujuan strategi, strategi, dan tata nilai ITS sesuai dengan Rencana Strategis ITS 2015-2020 dan Rencana Induk Pembangunan ITS 2016-2040. Komponen strategis ini digunakan sebagai dasaran dalam mengidentifikasi aspekaspek pada Organization Capital Readiness ITS.

\section{B. Pengumpulan Data - Hasil Benchmark}

Pada bagian ini akan dilakukan benchmark terhadap organisasi profit dan non profit untuk memahami dan membandingkan keadaan ITS dalam melakukan manajemen perubahan seiring perubahan status PTNBH sehingga mendapatkan cara untuk mengembangkan organisasinya, utamanya dalam organization capital. Adapun objek benchmark pada penelitian ini adalah Universitas Airlangga yang menggunakan framework Balanced Scorecard dalam menyusun OCR; Institut Teknologi Bandung yang pernah diukur oleh Kementerian Pendidikan dan Buday a Indonesia dimana dalam sistem pengukuran maturitas organisasi ITB berdasarkan Pedoman Penilaian dan Strategi Peningkatan Maturitas Sistem Pengendalian Intern Pemerintah pada Peraturan Kepala Badan Pengawasan Keuangan dan Pembangunan Republik Indonesia Nomor 4 Tahun 2016; dan PT. Peembangkit Jawa Bali Services dimana menggunakan 
Tabel 6 .

Perhitungan Pencapaian Level Maturitas OCR ITS

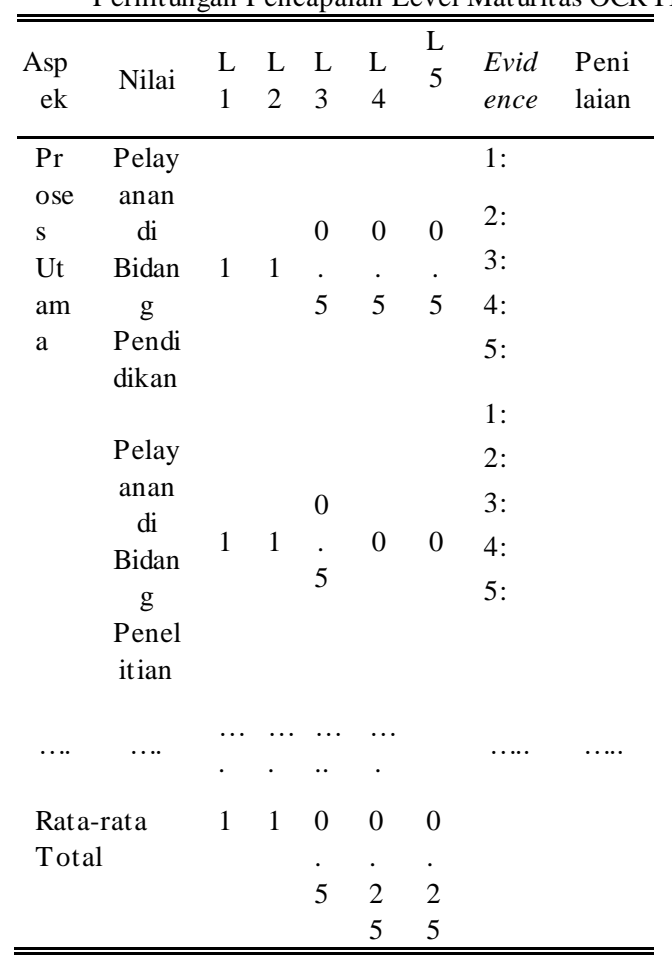

framework Process and Enteprise Maturity Model dalam mengembangkan OCR-nya.

\section{C.Aspek dan Nilai OCR ITS}

Berdasarkan komponen strategis yang dimiliki oleh Institut Teknologi Sepuluh Nopember, maka dilakukan penyusunan aspek-aspek Organization Capital Readiness ITS (Tabel 2). Aspek yang digunakan berbasis pada Organization Readiness Assessment System. Aspek-aspek dan nilai-nilai pada Organization Capital Readiness ITS. (Gambar 1)

Selanjutnya dilakukan pendefinisian tiap nilai dan penurunan nilai menjadi sub-nilai.

\section{D.Rancangan Maturity Model}

Pada tahap ini akan dilakukan perancangan maturity model yang ada di Institut Teknologi Sepuluh Nopember berdasarkan cakupan nilai yang ada pada setiap aspek pada Organization Capital Readiness ITS. Kerangka yang digunakan adalah Organization Maturity Model yang terdiri atas 5 level. Adapun dasaran dalam pembuatan maturity model ini adalah Rencana Strategis ITS 2015-2020, Rencana Induk Pengembangan ITS 2016-2040, dan studi literatur mengenai maturity model dan kondisi ideal dari tiap nilai pada Organization Capital Readiness di ITS. Bentuk dari bukti-bukti pencapaian level maturitas OCR ITS dapat dilakukan melalui kuesioner lanjutan, wawancara, pemeriksaan dokumen, pengamatan terhadap aktivitas/proses, dan pengamatan terhadap kondisi lapangan dimana tetap disesuaikan dengan Renstra ITS dan Renip ITS. Sedangkan penanggung jawab dari masing-masing nilai disesuaikan dengan Peraturan Rektor ITS Nomor 10 Tahun 2016 mengenai Organisasi dan Tata Kerja ITS Peraturan Pemerintah Nomor 54 Tahun 2015. Berikut merupakan kerangka dari model maturitas OCR ITS. Untuk model maturitas OCR secara keseluruhan terdapat pada Tabel 3.
Tabel 5 .

Organization Change Agenda

\begin{tabular}{|c|c|c|c|c|}
\hline & $\begin{array}{c}\text { Organiza } \\
\text { tion } \\
\text { Change } \\
\text { Agenda } \\
\end{array}$ & Definisi & $\begin{array}{l}\text { Strate } \\
\text { gi } \\
\text { Objek } \\
\text { tif } \\
\end{array}$ & $\begin{array}{c}\text { Eevide } \\
\text { nces }\end{array}$ \\
\hline 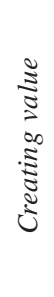 & $\begin{array}{l}\text { Custome } \\
\text { r driven }\end{array}$ & $\begin{array}{l}\text { Melakukan } \\
\text { perencanaan } \\
\text { dan strategi } \\
\text { sesuai dengan } \\
\text { permintaan } \\
\text { atau ekspektasi } \\
\text { pelanggan }\end{array}$ & $\begin{array}{l}\text { Menci } \\
\text { ptaka } \\
\mathrm{n} \\
\text { buday } \\
\text { a } \\
\text { pelang } \\
\text { gan } \\
\text { sentris }\end{array}$ & $\begin{array}{l}\text { Survei } \\
\text { pegaw } \\
\text { ai } \\
\text { Survei } \\
\text { pelang } \\
\text { gan }\end{array}$ \\
\hline 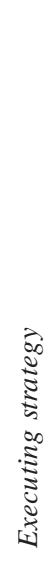 & $\begin{array}{l}\text { Akuntabi } \\
\text { litas }\end{array}$ & $\begin{array}{l}\text { Kemampuan } \\
\text { organisasi } \\
\text { dalam } \\
\text { menjadikan } \\
\text { transparan dan } \\
\text { akuntabel } \\
\text { sebagai prinsip } \\
\text { atau karakter } \\
\text { kerja dimana } \\
\text { tugas pokok } \\
\text { dan fungsi } \\
\text { masing-masing } \\
\text { stakeholder } \\
\text { akan } \\
\text { dipertanggungj } \\
\text { awabkan }\end{array}$ & $\begin{array}{l}\text { Memb } \\
\text { uat } \\
\text { nilai } \\
\text { perusa } \\
\text { haan, } \\
\text { penca } \\
\text { paian } \\
\text { buday } \\
\text { a yang } \\
\text { baik }\end{array}$ & $\begin{array}{l}\text { Survei } \\
\text { pegaw } \\
\text { ai }\end{array}$ \\
\hline & $\begin{array}{l}\text { Kerjasam } \\
\text { a }\end{array}$ & $\begin{array}{l}\text { Proses bekerja } \\
\text { yang } \\
\text { melibatkan } \\
\text { sekelompok } \\
\text { orang untuk } \\
\text { mencapai } \\
\text { tujuan } \\
\text { organisasi }\end{array}$ & $\begin{array}{l}\text { One } \\
\text { team- } \\
\text { one } \\
\text { dream }\end{array}$ & $\begin{array}{l}\text { Persen } \\
\text { tase } \\
\text { pegaw } \\
\text { aiPerc } \\
\text { ent of } \\
\text { people } \\
\text { rotted }\end{array}$ \\
\hline
\end{tabular}

\section{E. Perancangan Mekanisme Sistem Pengukuran OCR ITS}

Pada bagian ini akan dijelaskan mengenai rancangan mekanisme sistem pengukuran Organization Capital Readiness ITS. Berikut merupakan langkah-langkah dalam melakukan pengukuran OCR ITS yang mengadopsi dari Perka Nomor 4 Tahun 2016 mengenai Penilaian Maturitas Sistem Pengendalian Intern Pemerintah yang terdiri dari 3 tahap; tahap perencanaan, tahap pelaksanaan, dan tahap pelaporan.

1. Tahap Perencanaan

- Kantor Penjamin Mutu (KPM) ITS sebagai pihak yang bertanggung jawab atas sustainabilitas OCR ITS sesuai dengan Perek ITS Nomor 10 Tahun 2016.

- Tim dari KPM terdiri dari Kepala Kantor Penjaminan Mutu, Ketua Unit Penjaminan Mutu Akademik, dan Ketua Unit Penjaminan Mutu Non-Akademik. Kemudian, pada tim counterpart terdiri dari Ketua Tim Mutu Fakultas, Direktur Direktorat Akademik, Direktur Direktorat Kemahasiswaan, Direktur Direktorat Sumber Daya Manusia dan Organisasi (SDMO), Direktur Direktorat Pengembangan Teknologi dan Sistem Informasi (PTSI), Kepala Lembaga Penelitian dan Pengabdian kepada Masyarakat (LPPM), dan Direktur Direktorat Inovasi, Kerja Sama, dan kealumnian (IKSK). 
- Tujuan dari asesmen ini adalah untuk mengetahui level maturitas Organization Capital Readiness di Institut Teknologi Sepuluh Nopember. Periode peninjauan ini dilakukan per enam bulan dan ruang lingkupnya adalah unit kerja di Institut Teknologi Sepuluh Nopember

2. Tahap Pelaksanaan

- Pembagian kuesioner awal kepada unit kerja ITS terkait dimana target dari tiap ketercapaian evidence di setiap nilai OCR ITS disesuaikan dengan kebutuhan pada RENSTRA ITS 2015-2020 dan RENIP ITS 20162040. Berikut merupakan contoh kerangka kuesioner awal pengukuran OCR ITS. (Tabel 4)

- Setiap nilai memiliki 5 pernyataan yang menunjukkan 5 level pada model maturitas OCR ITS. Apabila unit kerja mengisi "Tidak" pada pernyataan terntentu maka untuk pernyataan seterusnya jawabannya adalah "Tidak". Jika berkebalikan, maka konsistensi unit kerja perlu diragukan.

- Penilaian level maturitas awal OCR ITS dengan merata-rata skor nilai OCR berdasarkan level maturitasnya. Adapun Skor "Ya" = 1 dan Skor "Tidak" $=0$.

- Asesmen isitasi/lapangan untuk memverifikasi jawaban responden berdasarkan bukti-bukti (evidences) dan melakukan pencatatan atas ketidaksesuaian. Bentuk dari bukti-bukti pencapaian level maturitas OCR ITS dapat dilakukan melalui kuesioner lanjutan, wawancara, pemeriksaan dokumen, pengamatan terhadap aktivitas/proses, dan pengamatan terhadap kondisi lapangan.

- Perhitungan pencapaian level maturitas OCR ITS Regulasi pengukuran OCR ITS dijelaskan pada Tabel 5 .

1. Untuk setiap level maturitas dan komponennya terdapat pernyataan level L-1 hingga L-5.

2. Kebenaran pernyataan ini dijawab dengan salah satu ukuran:

- Merah bila kebenarannya kurang dari $20 \%$ dan diberi nilai 0

- Kuning bila kebenarannya antara $20 \%$ hingga $80 \%$, diberi nilai 0.5

- Hijau bila kebenarannya lebih dari $80 \%$ diberi nilai 1

3. Nilai setiap level diperoleh dengan merata-ratakan kolom level yang bersangkutan.

Level $x=$

Ejumiah skor tiap nilai pada level yang sama Jumiah nilai yang ada pada OCR

4. Maksimum nilai untuk setiap level adalah 1.

5. Untuk mencari nilai maturitas (level) maka jumlahkan nilai $\mathrm{L}-1+\mathrm{L}-2+\mathrm{L}-3+\mathrm{L}-4+\mathrm{L}-5$ dengan syarat bahwa bila nilai maturitas sebelumnya tidak sama dengan satu maka tidak boleh ditambahkan dengan nilai maturitas berikutnya.

6. Misalnya $\mathrm{L}-1=1, \mathrm{~L}-2=1, \mathrm{~L}-3=0.5, \mathrm{~L}-4=0.25, \mathrm{~L}-5=0.25$ maka level maturitasnya adalah $1+1+0.5=2.5$.

7. Nilai 1 diperoleh dari L-1 dan $\mathrm{L}-2=1,0.5$ dari L-3 Nilai L-4 dan L-5 tidak diperhitungkan karena L-3 belum sama dengan 1 (belum melampaui level ini).
3. Tahap Pelaporan

Pada tahap pelaporan dibuat laporan penilaian maturitas Institut Teknologi Sepuluh Nopember yang memuat identifikasi laporan; tujuan dan ruang lingkup asesmen; rincian program AMI (asesor, responden, tanggal, dan area asesmen); hasil penilaian level maturitas awal; ringkasan ketidaksesuaian beserta bukti pendukung (jika ada); dan saran perbaikan kedepannya untuk ITS.

\section{F. Perancangan Mekanisme Sistem Penyusunan Perubahan Organization Capital ITS}

Perubahan Organization Capital dengan framework Organization Change Agenda dilakukan oleh Kantor Penjaminan Mutu ketika terdapat perubahan peta strategi yang memengaruhi iklim organisasi. Pada penyusunannya terdiri dari tahap perencanaan, tahap pelaksanaan, dan tahap pelaporan.

1. Tahap Perencanaan

Melakukan pertimbangan antara Laporan Penilaian Maturitas ITS dan arah perubahan pada peta strategi ITS. Kemudian, dilakukan peninjauan kembali as pek/nilai yang perlu dilakukan perubahan dengan melakukan forum group discussion (FGD) atau rapat yang membahas mengenai urgensitas perubahan dan aspek/nilai yang menjadi prioritas utama dalam melakukan penyusunan perubahana organization capital ITS.

2. Tahap Pelaksanaan

Setelah itu, dilakukan pengkategorian nilai-nilai perubahan pada OCR tergolong dalam menciptakan nilai (creating value) atau menjalankan strategi (executing strategy). Nilai-nilai perubahan tersebut didefinisikan kembali sesuai dengan ekspektasi ke depannya dan dilakukan perubahan pada tujuan strategis serta indikator pengukuran/evidence-nya.

3. Tahap Pelaporan

Pada tahap pelaporan dibuat laporan perubahan organization capital pada OCR ITS yang memuat identifikasi laporan; tujuan dan ruang lingkup perubahan; hasil perubahan dengan Organization Change Agenda. (Tabel 6)

\section{ANALISIS DAN INTERPRETASI DATA}

Institut Teknologi Sepuluh Nopember merupakan salah satu perguruan tinggi negeri di Surabaya, Jawa Timur. Berdasarkan Peraturan Pemerintah Nomor 83 Tahun 2014, Institut Teknologi Sepuluh Nopember ditetapkan sebagai salah satu perguruan tinggi yang mengalami perubahan status dari PTN-BLU berubah menjadi PTNBH. Hal ini menyebabkan ITS memiliki kewenangan untuk mengelola organisasi, keuangan, sumber daya manusia, dan infrastruktur dengan tata kelola yang baik. Transformasi budaya mutu dalam organisasi dan sistem manajemen ITS juga dibutuhkan untuk memenuhi tuntutan Good University Governance dan World Class University yang sejalan dengan agenda pembangunan Indonesia dan global pasca 2015 dari Xillenium Development Goals menuju Sustainable Development Goals.

Secara umum, ITS memiliki fungsi dan organ yang bergerak untuk menjaga sustainabilitas organisasi, yaitu Kantor Penjaminan Mutu. Namun, pada penjaminan mutu 
organisasi perlu adanya peningkatan kapabilitas organisasi agar tidak ada pengetahuan yang hilang (knowledge loss), dan dapat menjaga sustainabilitas pengembangan nilai/aspek pada organisasi bersifat dinamis sehingga apabila organisasi tidak memiliki acuan dalam memahami posisi organisasi akan terjadi perbedaan pandangan/persepsi antar individu. Dengan mengembangkan organization capital readiness di ITS, maka dapat menciptakan keselarasan pada tujuan proses bisnis internal yang terintegrasi satu sama lain dimana dapat membantu organisasi ITS dalam mencapai potensi produktivitas yang maksimal dan sinergitas pada ITS, serta ITS dapat memahami posisinya di tengah persaingan kualitas institusi dengan lebih mudah dan akurat.

\section{KESIMPULAN/RINGKASAN}

Pada perancangan model maturitas Organization Capital Readiness digunakan dokumen-dokumen perencanaan yang dapat menjadi bahan pertimbangan dalam perancangan yang dilakukan, seperti Rencana Strategis ITS 2015-2020 dan Rencana Induk Pengembangan ITS 2016-2040. Selain itu, digunakan pendekatan Organization Maturity Model dalam merancang model maturitas OCR ITS sehingga terdapat 5 tingkat/level maturitas didalamnya. Aspek-aspek pada Organization Capital Readiness menggunakan framework Organization Readiness Assessment System yang disesuaikan dengan kebutuhan organisasi Institut Teknologi Sepuluh Nopember yang terdiri dari proses utama, pendekatan manajemen, budaya, sinergitas, dan sikap terhadap perubahan. OCR merupakan tanggung jawab Kantor Penjamin Mutu dengan periode peninjauan per enam bulan sekali dengan ruang lingkup unit kerja di ITS.

\section{DAFTAR PUSTAKA}

[1] Aradea, Ade Yuliana, and Hidayatullah Himawan, "Penerapan Change Management untuk Peningkatan Proses Bisnis dalam Meraih Keunggulan Kompetitif Organisasi," in Seminar Nasional Informatika (semnasIF), 2010, pp. E27E36.

[2] R. S. Kaplan and D. P. Norton, "Strategy Maps - Converting Intangible Assets Into T angible Outcomes," 2004. 